\title{
Research of the Optimum Functioning Sewage Biological Purification Plants in Production of Polyols
}

\section{Miroshnichenko N, Gramatiuk S, Telegin V, Zhukov V, Zaytseva O and Rezunenko YK*}

Kharkiv National Medical University, Kharkiv, Ukraine

\begin{abstract}
The influence of some polyols on active silt state for estimation of efficiency of sewage biological purification plants has been studied. It was established the limiting concentrations of polyols in sewage, that don't violate the processes of biological purification. In the presence of high concentrations of polyols in sewage it is necessary to use activators of organic substrates biotransformation.
\end{abstract}

Keywords: Polyoxypropylenpolyols; Sewage biological purification; Active silt

\section{Introduction}

Preservation of reservoirs from pollution by industrial sewage is one of the most important tasks of the national economy. It is known that the bad purification of industrial sewage leads to the reservoirs pollution, harms to fishing industry and worsens sanitary conditions of water-supply and water-use. The basic amount of sewage in the production of polyols formed at the stage of catalyst preparation, adsorption drying and cleaning products, washing filter presses returnable packaging and equipment, as well as their rinsing. The sewage of polyols production have hydrocarbons, ethers, aldehydes, ketones, alcohols and other low molecular weight organic impurities of hydrolytic degradation and thermal oxidation [1].

Many of these chemicals are well studied in regard to hygiene. In certain concentrations, they change the organoleptic properties of water, violate processes of natural self-purification of reservoirs, and have a toxic effect on the organism of warm-blooded animals. Most of them violate the function of the central nervous system, cardiovascular and respiratory systems, as with prolonged admission to the organism have a polytrophic action [2,3].

To render harmless sewage in polyols production the most widely combined method is used. Its essence is following: the boiler residuums are burned, and part of the sewage has purification in the biological structures. With eco-hygiene products, this method has a drawback - the thermal deactivation pollutes the air space by thermal decomposition products, which represents a danger to public health. In some industries the method of vapor-phase thermocatalytic oxidation is used, which increases the degree of sewage purification up to $98 \%$ and by hygienic and technological indicators is the most effective. But despite the high efficiency of this method and reagentless it did not find a proper application in the production of polyols due to the economic unprofitability. Thus, the leading method is thermal incineration of the boiler residuums and next sewage biological purification.

In assessing the effect of toxic contamination of reservoirs methods of bioindication are widely used. By it the species diversity in biocoenosis of reservoir is considered as a measure of its structure and stability $[4,5]$. The objective function of such biological system is the maintenance of the highest possible level of destruction and utilization of organic matter.

The active silt state is mainly determined by the character of the load coming into the aerial tank, i.e. qualitative and quantitative composition of the sewage. At steady-state load on the sewage purification plant the steady state, is formed defined as standard which characterizing by the highest level of metabolism and energy. Changing the load goes beyond the functional standards, leads to disruption of the structural and functional organization of the biocoenosis of active silt and a qualitative change in the state of biological system.

In this connection the aim of this research was to determine the value of allowable load of the sewage on biological purification plants and the study of optimal conditions for their functioning.

\section{Materials and Methods}

The effect of polyols brands Laprol 4003 (L-4003) and Laproxid 703 (L-703) on the condition of active silt with subsequent determination of concentrations that do not have toxic effects on him was investigated. It is important to determine the effectiveness of the structures and in the event of the sewage entrance on a biological purification in a volley.

To assess the quality (I) of the biosystem can use the criterion of quality, which takes into account the additive and multiplicative properties [6]:

$$
I=\sum_{i=1}^{n} \mu_{i} \varphi_{i}\left(x_{i}\right) \cdot \prod_{i=1}^{n} \omega_{i}\left(\varphi\left(x_{i}\right)\right.
$$

where $\phi_{\mathrm{I}}\left(\mathrm{x}_{\mathrm{i}}\right)$ is a factor that reflects the functional state of biological systems; $\mu_{\mathrm{i}}$-is coefficient installed as a result of the estimates of experts, and for ensuring normalization- $\sum \mu_{i}=1 ; \omega_{i}\left(\varphi\left(x_{i}\right)\right.$-is the penalty function of the corresponding state factor that reflects the identity of the described object to the model, which is, for example, in the odd set of the corresponding algorithm.

The multiplicative part of the quality criterion contains information about the functional properties of biological system. It is known for the given level of the biocoenosis the highest quality of biosystem is ensured

*Corresponding author: Rezunenko YK, Kharkiv National Medical University Kharkiv, Ukraine, E-mail: dr.rezunenkoy.k@gmail.com

Received November 27, 2012; Accepted December 18, 2012; Published December 21, 2012

Citation: Miroshnichenko N, Gramatiuk S, Telegin V, Zhukov V, et al. (2012) Research of the Optimum Functioning Sewage Biological Purification Plants in Production of Polyols. Clin Exp Pharmacol S5:002. doi:10.4172/2161-1459.S5-002

Copyright: () 2012 Miroshnichenko N, et al. This is an open-access article distributed under the terms of the Creative Commons Attribution License, which permits unrestricted use, distribution, and reproduction in any medium, provided the original author and source are credited. 
at the maximum possible value of the coefficient of species diversity, and the number of species in biocenosis is a finite quantity, which depends on the type of nutrient substrate and conditions of existence. Given the properties of the penalty function to strive depending on the value of factor to the two limit values, namely $\omega_{\mathrm{i}}\left(\varphi\left(\mathrm{x}_{\mathrm{i}}\right) \rightarrow 0\right.$ at a value $\varphi_{\mathrm{i}}\left(\mathrm{x}_{\mathrm{i}}\right)=0$, and $\omega_{\mathrm{i}}\left(\varphi\left(\mathrm{x}_{\mathrm{i}}\right) \rightarrow 1\right.$ when the value $\varphi_{\mathrm{i}}\left(\mathrm{x}_{\mathrm{i}}\right)$ in the optimal mode of biological system, in the simplest case, the multiplicative part can be represented as follows:

$$
\prod_{\mathrm{i}=1}^{\mathrm{n}} \omega_{\mathrm{i}}\left(\varphi_{\mathrm{i}}\left(\mathrm{x}_{\mathrm{i}}\right)= \begin{cases}\mathrm{K} / \mathrm{K}_{0} & \text { when } 0<\mathrm{K}<\mathrm{K}_{0} \\ 1 & \text { when } \mathrm{K} \geq \mathrm{K}_{0}\end{cases}\right.
$$

Where $\mathrm{K}-$ is number of species in given conditions; $\mathrm{K}_{0}-\mathrm{is}$ the number of species in the optimal conditions for the existence of a biosystem.

Additive part of the biosystem quality functional can be represented by a function of the entropy measure in the form of, for example, the entropy index of species diversity according to Shannon, calculated by the formula

$$
\mathrm{S}=-\sum_{\mathrm{i}=1}^{\mathrm{k}}\left(\mathrm{n}_{\mathrm{i}} / \mathrm{N}\right) \cdot \lg \left(\mathrm{n}_{\mathrm{i}} / \mathrm{N}\right)
$$

Where $\mathrm{k}$ - is number of species, units; $\mathrm{N}$ - is total number of organisms, thousands of specimens / $\mathrm{g} ; \mathrm{n}_{\mathrm{i}}-$ is the number of individuals of $\mathrm{i}$-th species, thousands of specimens/g.

Characteristics of species diversity are taken into account in the reliability index R. In addition, in the additive part it is necessary to take into account parameters, reflecting the protective function of biological system. Functional properties of biological system to provide structural and functional integrity and regulation of protective mechanisms for the given active silt is proposed to evaluate by the formula

$$
\mathrm{I}=(0.86 \mathrm{R}+0.14 \mathrm{a}) \cdot \mathrm{K} / \mathrm{K}_{0},
$$

where $\mathrm{R}$ - is an indicator of reliability of the biocoenosis of active silt, $\mathrm{cu}$; $\mathrm{a}-\mathrm{is}$ an indicator of the enzyme activity response amplitude in given conditions of active silt operating, $\mathrm{cu} ; \mathrm{K}, \mathrm{K}_{0}$-is the number of species of aquatic organisms of active silt at the time of measurement, and for optimal work, respectively, rel. units.

The coefficients 0.86 and 0.14 are installed as a result of computer simulation to optimize the model parameters based on the actual characteristics of the active silt of aerial tank. A factor that reflects the protective function of biological system, defined as the amplitude of the silt response to the effect of sewage by catalase activity according to the formula

$$
a=I \cdot \frac{\left(K A_{\text {wash off }}-K A_{\text {unwash off }}\right)_{t}}{\left(K A_{\text {wash off }}-K A_{\text {unwash off }}\right)_{c}}
$$

Where I - is the criterion of quality; and $\mathrm{KA}_{\text {wash off }}$ and $\mathrm{KA}_{\text {unwash off }}$ -catalase activity of silt after 20 minutes of contact with the sewage under aeration for the washed off and unwashed off from sewage silt, respectively, $\mathrm{mg} \mathrm{H}_{2} \mathrm{O}_{2} / \mathrm{mg}$ silt.

Based on the fact that the active silt microfauna is the most sensitive to the action of toxic substances, it is proposed to evaluate the reliability of its operation on the basis of aquatic organisms quantitative in the form of the probability of failure-free operation of the biosystem, which is calculated by the formula

$$
\mathrm{R}=1-\exp \left(\frac{\Delta \mathrm{t}}{\mathrm{T}} \cdot \mathrm{h}\left(1-\frac{\mathrm{K}}{\mathrm{K}_{0}} \cdot \frac{\mathrm{S}_{\mathrm{i}}}{\mathrm{S}_{0}}\right)\right)
$$

where $\Delta t$ - is the time duration from the contact of the active silt with sewage up to the moment of hydro biological analysis, $\mathrm{h}$; $\mathrm{T}$-is the characteristic time of operation of silt, i.e. turnover time of the active silt in the purification technologies, $\mathrm{h} ; \mathrm{K} / \mathrm{K}_{0}$-is the coefficient of species diversity, relative units; $\mathrm{S}_{\mathrm{i}}$-is the entropy index of species diversity (by Shannon-Wiener) analyzed biocoensis, rel. units; $\mathrm{S}_{0}-$ is the entropy index of biocoenosis, operating under optimal conditions.

Function of the probability of failure-free operation of active silt $\mathrm{R}$ varies from 0 to 1 . In addition, $\mathrm{R}$ tends to 1 in the normal course of the purification process and to zero-in the complete degradation of biocoenosis.

For a comparative assessment of the damaging effects on the active silt it is used the relative change of the reliability $(\mathrm{R})$, calculated by the formula

$$
\Delta \mathrm{R}=1-\frac{\mathrm{R}_{\mathrm{i}}}{\mathrm{R}_{\mathrm{c}}}
$$

Where $\mathrm{R}_{\mathrm{i}}$-is the index of reliability of active silt operating in an experiment, rel. units; $R_{c}$ - is the indicator of reliability of active slit in the control, rel. units.

For a comparative evaluation of the effectiveness of the active silt used the relative content of organic matter in treated water by index of CCO (chemical consumption of oxygen), which was calculated as follows:

$$
\Delta \mathrm{CCO}=1-\frac{\mathrm{CCO}_{\mathrm{i}}}{\mathrm{CCO}_{\mathrm{c}}}
$$

Where $\mathrm{CCO}_{\mathrm{i}}$-is $\mathrm{CCO}$ by the water in the experiment, $\mathrm{mg} / \mathrm{l} ; \mathrm{CCO}_{\mathrm{c}}-$ is $\mathrm{CCO}$ in the control, $\mathrm{mg} / \mathrm{l}$.

Experiments to assess the effect of chemicals in the cleaning process were conducted in model mixers, of 1 liter volume, in which the active silt from the regenerator of industrial aerial tanks was placed. In the control aerial tank one-off household effluent water in a ratio 1:1 to active silt was placed, and in the experienced - the investigated substances in a given concentration. The mixture is aerated for $4 \mathrm{~h}$. after then hydrobiological analysis of active silt by method of calibrating drop carried out. Then, after $12 \mathrm{~h}$ in all aerial tanks we determined $\mathrm{CCO}$ by the treated water in filtered samples by dichromate method. The concentration of active silt was determined by dry substance.

\section{Results of Research and their Discussion}

To assess the optimal conditions for the sewage purification plants functioning polyols L-4003 and L-703 are used. The half-life of these substances at the initial their concentration of $4 \mathrm{~g} / \mathrm{l}$ for a year of exposure could not be established that bears witness to the high stability. Normal functioning of the active silt was observed in the presences of L-703 in concentrations up to $30 \mathrm{mg} / \mathrm{l}$. Increasing concentrations of L-703 from 30 to $243 \mathrm{mg} / \mathrm{l}$ resulted to activation of biocoenosis of active silt. At concentrations from $729 \mathrm{mg} / \mathrm{l}$ and above loss of biocoenosis was noted. The results suggest that L-703 in concentrations up to $729 \mathrm{mg} / \mathrm{l}$ hasn't toxic effect on active silt. A similar effect we observed when evaluating 
Citation: Miroshnichenko N, Gramatiuk S, Telegin V, Zhukov V, et al. (2012) Research of the Optimum Functioning Sewage Biological Purification Plants in Production of Polyols. Clin Exp Pharmacol S5:002. doi:10.4172/2161-1459.S5-002

Page 3 of 3

the effect of L-4003: it is poorly exposed to oxidation and degradation; biological purification using active silt is ineffective; at concentrations up to $30 \mathrm{mg} / \mathrm{l} \mathrm{hadn't} \mathrm{effect} \mathrm{on} \mathrm{the} \mathrm{biocoenosis} \mathrm{of} \mathrm{active} \mathrm{silt.} \mathrm{The} \mathrm{toxic}$ properties of L-4003 appeared in concentrations higher than $81 \mathrm{mg} / \mathrm{l}$. The effecacy of biological purification from the L-703 and L-4003 was 50 , and $40 \%$ respectively.

Thus, in the course of studying the L-703 and L-4003 polyols influence on the active silt state in sewage biological purification plants we determined threshold and toxic concentrations. L-4003 at concentrations up to $30 \mathrm{mg} / \mathrm{l} \mathrm{had} \mathrm{no} \mathrm{effect} \mathrm{on} \mathrm{the} \mathrm{work} \mathrm{of} \mathrm{the} \mathrm{sewage}$ biological purification plants. L-703 at concentrations up to $243 \mathrm{mg} / \mathrm{l}$ and L-4003 at concentrations up to $81 \mathrm{mg} / \mathrm{l}$ increased the silt activity. Consequently, the concentrations of 243 and $81 \mathrm{mg} / \mathrm{l}$ for L-703 and L-4003, respectively, should be considered as threshold. At much higher concentrations polyols have a toxic effect on the biocoenosis of active silt and operation of sewage biological purification plants. The efficacy of biological purification from L-4003 is slightly higher than L-703, and is respectively $50 \%$ and $40 \%$, which makes this purification ineffective. In this connection there is need for improved methods of sewage purification. Based on the mechanisms of degradation of polyols, it follows that their decay is carried out by way of free radical oxidation. The initiator of these processes is reactive oxygen species $[1,7,8]$, which accelerate the mechanism of free radical oxidation of polyols. These results give reason to take into account this mechanism in the biological purification of sewage containing polyols, using activators of organic substrates biotransformation processes-ozone, chlorine, hydrogen peroxide, which will increase the efficiency of neutralization of sewage. Optimum conditions for the functioning of the sewage biological purification plants in the production of polyols should be considered as the concentrations of L-4003 and L-703 up to 81.0 and $243.0 \mathrm{mg} / \mathrm{l}$, respectively. At higher concentrations these plants are not capable of effectively neutralize the sewage containing polyols.

\section{References}

1. Zhukov VI, Popov LD, Zaitseva OV (2000) Simple and macrocyclic esters: scientific basis for the protection of water bodies. Kharkov, Tornadoes 438 .

2. Olga Zaitseva, Zhukov VI, Rezunenko JK, Laproksidov (1999) influence on the generative function and genetic system of white rats. Ecology and Medicine 2: $55-60$.

3. Zhukov VI, Zolotarevskaya LA, Grigorov VI, Zaitseva OV (1998) Structuralfunctional theory of the biological action radiotoxins. Kharkov, Base 225.

4. Slavinsky AS, MF Bialystok, Avdeeva EN (1983) Industrial plant to purify waste water production polyethers. Tashkent 60

5. Filippenko OD (1988) Aquatic toxicology. Moscow State University, Moscow 154.

6. Veselovsky VA (1987) Reliability and homeostasis of biological systems Science 96-101.

7. Yao J, Zhang JL, Wu YQ, Lu ZJ (2009) Contrasting study of erythritol and xylitol on Streptococcus mutans. 27: 603-605.

8. Herbst W, Hungar K (2004) Industrial Organic Pigments: Production, Properties and Applications. ( $3^{\text {rd }}$ edition), Wiley-VCH, Weinhein.

This article was originally published in a special issue, Pharmacology and 